\title{
Breast Self-Examination: Knowledge and Practice Among Female Secondary School Students in Delta State, Nigeria
}

\author{
Morenike O. Akpo ${ }^{1 *}$, Ademola M. Amosu ${ }^{2}$, Dora O. Akinboye ${ }^{3}$ \\ ${ }^{1,2,3}$ Department of Public Health, Babcock University, Ogun State, Nigeria
}

\begin{abstract}
Breast self-examination (BSE) is a preventive tool for early identification of breast changes and abnormalities. This study was aimed at assessing breast self-examination knowledge and practice among female secondary students in Delta State, Nigeria. This descriptive cross-sectional study was carried out among female senior secondary school students from selected public schools in Delta State, Nigeria. This study utilized a self-administered 59-item validated questionnaire for data collection from 216 consenting female students who volunteered to take part in the study. The knowledge and practice of breast self-examination were measured on 33 and 18 points reference scales, respectively. Data were analyzed using SPSS version 23.0. Frequency, mean, standard deviation and correlation analysis were reported. All statistical tests were at $5 \%$ level of significance.

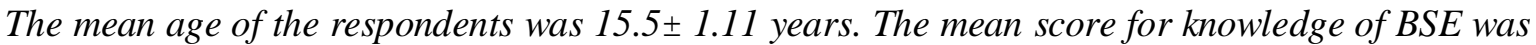
$5.8 \pm 3.8$ while the mean score for BSE practice was 7.3+2.1. Correlation analysis showed no significant relationship between knowledge and practice of BSE $(p=0.095, R=0.114)$. The overall knowledge and practice of BSE was very poor. This calls for the need to improve breast selfexamination advocacy among the adolescents; training and intervention programs to improve their knowledge as well as the regular practice of BSE.
\end{abstract}

Keywords: adolescents, Breast self-examination knowledge, Breast self-examination practice, Delta State, female secondary school students, Nigeria.

\section{Introduction}

Breast Self-Examination (BSE) involves both visual inspection and manual palpation of the breast. The aim is to detect breast abnormalities and changes early to enhance prompt medical attention and treatment. These breast changes and lumps may be benign or malignant. The methods and tools for generally assessing the breast include breast selfexamination (BSE), clinical breast examination (CBE) and mammography [1, 2, 3, 4, 5]. Other tools include magnetic resonance imaging (MRI) and digital breast tomosynthesis [6]. John Hopkins breast center Stated that [7], 40\% of diagnosed breast cancers are detected by women who feel a lump in their breast. This may mean that BSE is an important tool that makes a woman to be 'breast aware' $[3,6]$.

Breast self-examination is simple, easy to perform private, convenient, cost-effective and does not require the use of special equipment $[4,8,9]$. It is recommended that BSE should begin from 20 years of age $[10,11]$. However, it has also been advocated that BSE should commence earlier, starting from puberty and to continue throughout lifetime [12].

In developing countries where mammography is not readily available and clinical breast examination is not routinely done, breast self-examination remains the best option for women of all ages. Additionally, the adolescent breast has dense tissues which limit its sensitivity to mammography $[4,13,14]$.

The practice of BSE varies from country to country, from region to region, and among women of different levels of educational status. The practice of breast-self-examination has been reported to range from $19 \%$ to $43.2 \%$ in Nigeria $[15,16]$.

The World Health Organization defines individuals in 10-19 years age group as adolescents and the majority of secondary school students fall within this age group. The adolescent age is a transitory period from childhood to adulthood. It is associated with bodily changes, development of secondary sexual characteristics, including the breast. 
Promotion of positive preventive health behavior like BSE during this period may yield results that are carried on to adulthood. This is pertinent since the trend of development of breast abnormalities including breast cancer is increasing in females below 30 years of age $[17,18,19,20]$.

There are documented reports on BSE among women in the general population, but there are no previous reported studies on BSE among the female secondary school students in Delta state, more so that a previous study reported that benign breast tumor is common among the adolescent age group in this environment [18]. Hence the need to assess breast self-examination knowledge and practice among the female secondary school students in Delta State.

Establishing baseline knowledge and practice of BSE among this group of students will provide information for designing intervention programs to improve breast health and BSE skills among them and enhance policy making regarding the adolescent's health.

\section{General Objectives}

To assess the level of knowledge and practice of breast self-examination among female secondary school students in Delta State, Nigeria.

\section{Specific Objectives}

1. To determine the level of knowledge of the students on breast self-examination.

2. To determine the level of practice of breast self-examination among the students.

3. To determine if a relationship exists between the student's knowledge and Practice of BSE.

\section{Materials and Methods}

\section{Study Design}

This was a descriptive cross-sectional study carried out among female Senior Secondary School Two (SS2) students in public schools in Delta State, Nigeria.

\section{Study Area}

Two secondary schools were randomly selected from two local government areas in Delta State located in the South-South geopolitical zone of Nigeria. Ekpan secondary school was selected from Uvwie local government area and the other, Hussey College from Warri-South local government area. Uvwie is a gateway town in and out of the city of Warri. Warri-South local government area is predominantly riverine, and it is the commercial nerve center of the state. Both local government areas have several private and public secondary schools. Hussey College is one of the oldest and most prestigious colleges in the local government.

\section{Study Population}

The study population included female Senior Secondary Schools two (SS2) students of the selected schools. Other senior classes, SS1 and SS3 were excluded from participating. SS3 students were not allowed to participate because they were preparing for their school leaving examinations. The schools were randomly selected from the list of public schools in the two local government areas. Participation in this study was voluntary. Volunteers were obtained from all the arms of SS2 in the selected schools and only female SS2 students who were present in the school at the time of the study were allowed to participate in the study.

\section{Sample size Determination and Sampling Procedures}

The sample size calculation was adapted from Leslie-Kish formula.

$$
\mathrm{n}=\frac{(Z \alpha+Z \beta)^{2} \times(\mathrm{p} \times \mathrm{q})}{\mathrm{d}^{2}}
$$

The sample size (n) was calculated based on the following assumptions: $Z \alpha=$ Normal standard deviant at $95 \%$ confidence interval (1.96), $\mathrm{Z} \beta=$ Power at $80 \%$ (0.84), $\mathrm{q}=(1-\mathrm{P})$ where $\mathrm{P}=$ proportion of breast self-examination $=50 \%, \mathrm{~d}=$ level of Precision (0.1). The Calculated sample size was 196. After applying the $10 \%$ attrition rate, the final sample size was 216.

\section{Instrumentation}

The instrument for data collection for this study was a semi-structured self-administered questionnaire. The questionnaire was divided into three sections with 59 items. The 59 items were a mixture of multiple-choice questions and questions with categorical variables (yes/no/I don't know). Section A consisted of 
questions on the social demographic characteristics of the participants; Section B consisted of questions on knowledge of BSE (39 items) and Section C consist of questions on breast self- examination practice (15 items). Face and content validity was achieved by seeking opinions of experts in the field of Public health and Health promotion. The instrument was pilot-tested for its comprehensibly and clarity among a convenience sample of SS2 students from a non-participating school, who represent $10 \%$ of the of the calculated sample size. Modification of the questionnaire was however carried out based on the outcome of the pilot-testing before using it for final data collection. The overall reliability score (Cronbach alpha) was 0.74 .

\section{Measurement}

The respondents' knowledge score is measured on point rating scale with one point assigned to a correct answer and zero assigned to an incorrect answer. Participants who scored less than $50 \%$ of the knowledge questions were considered as having poor knowledge. Participants who scored between $50 \%$ and $75 \%$ were considered as average knowledge, and those who scored greater than $75 \%$ were classified as having good knowledge. The same was applied to the practice of breast selfexamination. The scores were grouped into poor practice, and good practice. Scores below $50 \%$ was grouped as poor practice while scores above $50 \%$ was grouped as good practice.

\section{Ethical Consideration}

Approval for the study was obtained from Babcock University Research and Ethics committee (reference number BUHREC036/20), the Chief Inspector of Education for Uvwie and Warri South local government area, as well as the principals of the participating schools. Informed consent was also obtained from the students.

\section{Data collection procedure}

Data was collected using self-administered questionnaire. This was achieved after the aim of the study was explained to the respondents and informed consent obtained from them, Confidentiality of information and anonymity was maintained.

\section{Data Analysis}

The data collected were entered into a personal computer and analyzed using the Statistical Package for the Social Sciences (SPSS) for Windows, version 23.0. Descriptive statistics (frequency distributions) for demographic characteristics; responses of the respondents, means and standard deviations were transformed into weighed aggregate scores. Correlational analysis between knowledge level of breast self-examination and breast self-examination practice were measured using Pearson Correlation. Significant level was set at $\mathrm{p}<0.05$ for all statistical analysis.

\section{Results}

A total of 216 students participated in this study, and the response rate was $100 \%$.

\section{Socio-demographic Characteristics of the Participants}

The socio-demographic characteristics of the students include their age, class, tribe, marital status and religion. The mean age for the respondents in the study was $15.5 \pm 1.11$ years. Most of the respondents were between 15 years and 16 years old (Table 1). Majority, 72 $(33.3 \%)$, were 16 years and $68(31.5 \%)$ were 15 years old. All the respondents $216(100 \%)$ were females in SS2 class. Majority 69 (31.9\%) were Urhobo by tribe followed by Ibo $28(13 \%)$, Itsekiri 25(11.6\%), Isoko 21(9.7\%), Ijaw $19(8.8 \%$ and Okpe 14(6.5\%). Other tribes accounted for $40(18.5 \%)$ of the respondents. All the respondents $216(100 \%)$ were single and $212(98.1 \%)$ of them were Christians.

\section{Knowledge of Breast Self-Examination}

Knowledge of breast self-examination was measured on a 33-point reference scale and the mean score was $5.8 \pm 3.8$ (Table 2). Ninety-three $(43.1 \%)$ of the respondents have heard of breast self-examination. Thirty-four $(15.7 \%)$ heard of it from the internet, $32(14.8 \%)$ from mother, and $30(13.9 \%)$ from school. Just a few of the respondents $83(38.4 \%)$ knew the meaning of breast self-examination. Forty-seven $(21.8 \%)$ respondents indicated that they have had previous training on BSE. Ninety-two (42.6\%) respondents asserted that they do not know the age BSE should commence and more than half 
of the respondents, $182(84.2 \%)$, did not know that BSE is done monthly. Regarding the positions taken during BSE, only 35 (16.4\%) respondents knew that it can be performed in a lying down position while only 4 (17.1\%) knew it can be done standing in front of a mirror.
Many of the respondents, 179 (82.8\%), do not know that the pads of the three middle fingers are used when examining the breast. Overall, $168(77.7 \%)$ respondents do not know the positions taken while performing BSE.

Table 1. Socio-Demographic Characteristics of the Respondents

\begin{tabular}{|c|c|c|}
\hline \multirow[t]{2}{*}{ Variables } & \multicolumn{2}{|c|}{ Respondents in the study $(\mathrm{N}=216)$} \\
\hline & Frequency $(\mathrm{N}=216)$ & Percentage $(\%)$ \\
\hline \multicolumn{3}{|c|}{ - 1 a } \\
\hline 13 years & 1 & 0.5 \\
\hline 14 years & 31 & 14.4 \\
\hline 15 years & 68 & 31.5 \\
\hline 16 years & 72 & 33.3 \\
\hline 17 years & 32 & 14.8 \\
\hline 18years & 10 & 4.6 \\
\hline 19years & 2 & 0.9 \\
\hline \multicolumn{3}{|l|}{ Gender } \\
\hline Male & 00 & 0.00 \\
\hline Female & 216 & 100 \\
\hline \multicolumn{3}{|l|}{ Tribe } \\
\hline Ibo & 28 & 13.0 \\
\hline Ijaw & 19 & 8.8 \\
\hline Itsekiri & 25 & 11.6 \\
\hline Urhobo & 69 & 31.9 \\
\hline Isoko & 21 & 9.7 \\
\hline Okpe & 14 & 6.5 \\
\hline Others & 40 & 18.5 \\
\hline \multicolumn{3}{|c|}{ Marital Status } \\
\hline Single & 216 & 100 \\
\hline Married & 00 & 0.00 \\
\hline \multicolumn{3}{|l|}{ Religion } \\
\hline Christian & 212 & 98.1 \\
\hline Muslim & 4 & 1.9 \\
\hline \multicolumn{3}{|c|}{ Academic level } \\
\hline SS2 & 216 & 100 \\
\hline Others & 00 & 0.00 \\
\hline
\end{tabular}

Table 2. Summary of Mean Scores

\begin{tabular}{|l|l|l|l|}
\hline \multirow{2}{*}{ Variables } & \multicolumn{3}{|c|}{ Respondents in the study (N= 216) } \\
\cline { 2 - 4 } & Rating Scale & Mean & SD \\
\hline Level of knowledge of BSE & 33 & 5.8 & 3.8 \\
\hline Level of BSE Practice & 18 & 7.3 & 2.1 \\
\hline
\end{tabular}




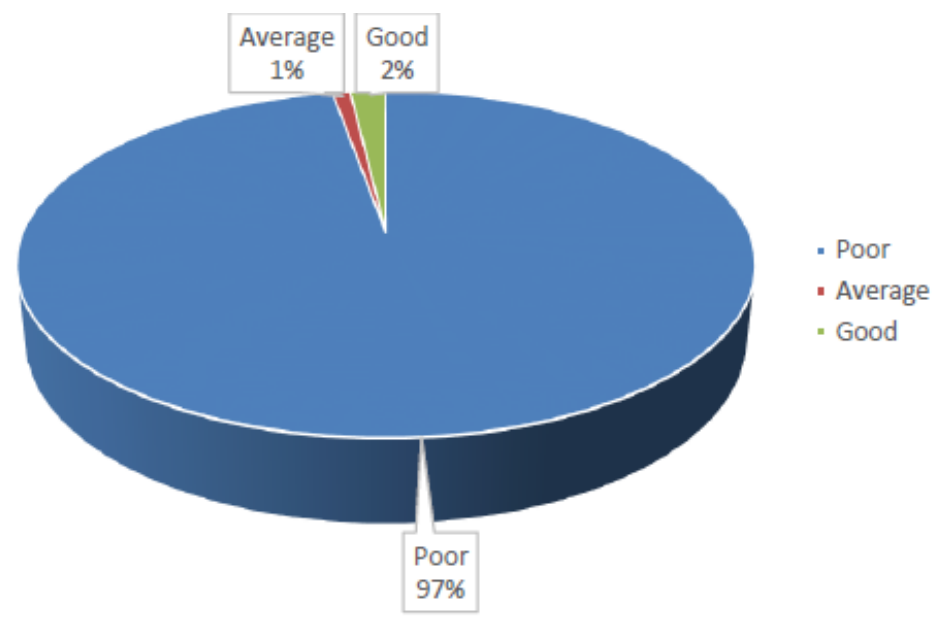

Figure 1. Knowledge of Breast Self-Examination $(n=216)$

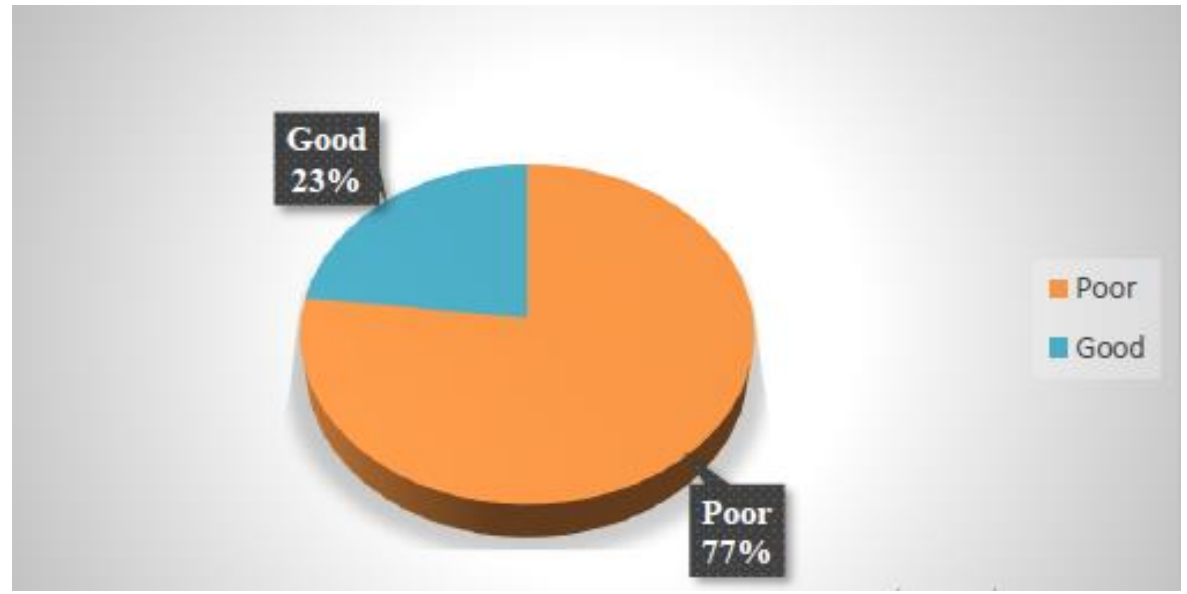

Figure 2. Practice of Breast Self-Examination $(\mathrm{n}=216)$

\section{Practice of Breast Self-Examination}

The practice of breast self-examination was measured on 18 points reference scale. The mean score was $7.3 \pm 2.1$ (Table 2) with $77 \%$ of the participants having poor practice of BSE (Fig 2). One hundred and eighty-nine (87.5\%) respondents have never performed a BSE while only $27(12.5 \%)$ of the respondents have ever performed BSE. Seven (3.2\%) respondents perform BSE monthly, while $12(5.6 \%)$ perform BSE anytime. Furthermore, only 8 $(2.8 \%)$ perform after their mensuration.

Though the practice was poor, the respondents gave reasons for engaging in BSE practice. Eighteen $(8.3 \%)$ said they are aware of the benefits, $22(10.2 \%)$ 'to avoid being diagnosed with breast cancer', 19 (8.8\%) 'Knew someone with breast cancer', 19 (8.8\%) 'to avoid the breast being cut off' and 20 $(9.25 \%)$ have of a family history of breast cancer. The most common reasons given by the respondents $(186 ; 86.1 \%)$ for not engaging in BSE was 'I do not know how to do it', fourteen $(6.6 \%)$ said they never knew about BSE, 32 (14.8\%) forgetfulness and $21(9.7 \%)$ do not want to be diagnosed as having breast cancer. Additional reasons given for not engaging in BSE practice include: 'I am not at risk of breast cancer or breast problems, I am not up to the age of doing BSE, I do not feel comfortable touching my breast and it is time-consuming'.

Correlation analysis was done to determine if there was any relationship between the level of knowledge of breast self-examination and the practice of breast self-examination. From the analysis, there was a positive relationship, but there was insufficient statistical evidence to conclude that there was significant relationship between the variables $(\mathrm{p}=0.095, \mathrm{R}=0.114)$.

\section{Discussion}

Breast self-examination is the simplest and safest way of identifying breast abnormalities 
early, and quickest way of getting familiar with one's own with regular practice. This is of great importance to the adolescent female who has limited options of breast screening tools.

The results obtained from the study showed that the level of knowledge of breast selfexamination and practice of breast selfexamination were poor. This indeed did not come as a surprise, though not welcoming because many females in this age group do not pay particular attention to their breast health and this is not included in their school curriculum.

More than $80 \%$ of the respondents scored below the mean score for the level of knowledge of BSE, and the practice of breast self-examination followed same with $76.9 \%$ of them having poor practice. Only $3.2 \%$ of respondent practice BSE monthly. The result is not totally different from that reported from similar studies across Nigeria, from different states using a similar group of senior secondary school students. They reported both poor knowledge and practice of BSE as it is the case with the present study [17, 21, 22, 23, 24, 25].

Similar findings have been reported among high school students outside Nigeria [26]. This problem is, therefore, not peculiar to Nigerian adolescents. This is because less emphasis is placed on breast health among the secondary school students, but more efforts seem to be directed towards older women. It should be remembered that both groups of women (the older women and the younger female secondary school students) are vulnerable to developing diseases of the breast including breast cancer though too common in the younger age group. Efforts should therefore be made to target this group of adolescents early with adequate knowledge and require skills in performing breast examination.

Lack of knowledge as to when and how BSE should be done were the most popular reasons cited by $86.1 \%$ of the respondents, as reasons for not practicing BSE. This can be said to be responsible for the poor practice of BSE among the respondents. This corroborates other similar studies [17, 22, 27].

Knowledge is antecedent to practice. It is the steppingstone to good practice and adoption of healthy behavior. Other reasons highlighted by the respondents that may also have accounted for the poor practice include perception of "not being at risk" and "not up to the age" of commencing BSE. This is the more reason why enlightenment and training about BSE should commence early in order to guide them and erase misconceptions they may have about BSE.

Students will benefit from inclusion of topics on breast health into their regular school curricula just as it with reproductive health. They need to know that being a woman is a risk factor for breast diseases, including breast cancer. There are previous reports of young females diagnosed with breast cancer between the ages of 14-16 years (Banjo, 2004). From the present study, just a few (8.3\%) respondents examine their breasts because they are aware of the benefits of doing so. This makes it essential for young females to be told about the benefits and limitations of BSE early so they can make an informed decision as to whether they want to adopt this practice.

Hearing about BSE does not translate into knowledge and practice as observed in this study where less than $50 \%$ of the respondents (43.1\%) have heard about BSE and yet the majority of those who have heard of BSE do not practice BSE. This outcome was found not to be too different from studies reported from Osun $(58.8 \%$ ) and $55.2 \%$ in Anambra State in Nigeria $[17,20]$. Among the Turkish students, a small percentage of them $(37.9 \%)$ were reported to have heard of BSE. The level of knowledge of BSE and practice of BSE among them were also reported as being poor. This invariably suggests that hearing or passing information is not enough. There is the need to engage the students, during the adolescent age, through continuous learning and practice in order to ensure adherence to BSE. This habit is expected to be carried on to adulthood. Educating young females early from the secondary school on breast self-examination and ensuring monthly and regular practice of BSE will have a greater and positive impact on the society, the family (sisters and mothers), friends and colleagues, in identifying breast abnormalities and preventing delay and late presentation in the hospital.

\section{Conclusion}

Considering the outcome of this study, there is the need to step up intervention programs to improve the knowledge of females in secondary 
school on breast health and preventive health practices regarding the breast. They seem to be the "neglected group" when it comes to issues of breast health. Though they are not likely to develop breast cancer at this age, they are at risk and are vulnerable to developing several breast abnormalities, including breast cancer. Therefore, empowering them with adequate knowledge and necessary skills to perform BSE will go a long way in securing their life and reducing morbidity and mortalities associated with breast diseases.

\section{Recommendations}

Breast health should be included in the secondary school curriculum covering different topics on the female breast. Teaching of BSE should be intensified beginning at this level, emphasizing the benefits and limitations of BSE.

Intervention programs, health talk, workshops and seminars should be organized from time to time for these students, for a continuous update of knowledge on issues related to female breast health.

The different platforms of social media can be used to disseminate information on BSE to the public.

\section{References}

[1] World Health Organization. (2020). Breast Cancer. Retrieved from https://www.who.int/cancer/prevention/diagnosisscreening/breast-cancer/en/.

[2] World Health Organization. (2020). Adolescent Health. Retrieved from https://www.who.int/southeastasia/healthtopics/adolescent-health.

[3] Centers for Diseases Control and Prevention. (2018). what is Breast Cancer Screening Retrieved from

https://www.cdc.gov/cancer/breast/basic_info/screen ing.html.

[4] Sani, A .M, \& Yau, S.L. (2018). Relationship between knowledge and practice of breast selfexamination among female workers in Sokoto, Nigeria. Obstetric and Gynecological International Journal. 9(3), 157-162. https//doi.org/ 10.15406/ogij.2018.09.00323.

[5] Takkar, N., Kochhar, S., Garg P, Pandey, A. K., Dalal, U.R, \& Handa, U. (2017). Screening methods (clinical breast examination and mammography) to
In addition, training of peer educators in schools should be encouraged to involve the female teachers and students. This will help to ensure sustainability and continuous practice.

\section{Strength of the study}

The questionnaire was worded in simple language, easy to understand by the respondents.

\section{Limitation}

The study respondents were all from public schools and in senior secondary school two. This may affect the generalization of this study to the entire female secondary school students in the state.

\section{Conflict of Interests}

The author declares that there is no conflict of interest.

\section{Acknowledgement}

The authors acknowledge the Chief Inspector of Education of the local government areas where the study took place, the principals, coordinating teachers of SS2 and all the students who took part in the study.

detect breast cancer in women aged 40-49 years. Journal of Mid-life Health, 8 (1), 2-10. Retrieved from

http://www.jmidlifehealth.org/text.asp?2017/8/1/2/2 01966.

[6] American Cancer Society. (2020). Recommendations for the Early Detection of Breast Cancer. Retrieved from https://www.cancer.org/cancer/breastcancer/screening-tests-and-early-detection/americancancer-society-recommenda.

[7] Johns Hopkins Breast Center. Breast Self-Exams. Retrieved from https://www.hopkinsmedicine.org/breast_center/trea tments_services/breast_cancer_screening/breast_self _exam.html.

[8] Kalliguddi, S., Sharma, S., \& Gore, C. A. (2019). Knowledge, attitude, and practice of breast selfexamination amongst female IT professionals in Silicon Valley of India. Journal of family medicine and primary care, 8(2), 568-572. https://doi.org/10.4103/jfmpc.jfmpc_315_18. 
[9] Shallso, S.A., Boru, J.D. Breast self-examination practice and associated factors among female healthcare workers in West Shoa Zone, Western Ethiopia: a cross-sectional study. (2019). BMC Research Notes 12, 637. https://doi.org/10.1186/s13104-019-4676-3.

[10] Sama, C. B., Dzekem, B., Kehbila, J., Ekabe, C. J., Vofo, B., Abua, N. L. ... Angwafo, F. (2017). Awareness of breast cancer and breast selfexamination among female undergraduate students in a higher teacher training college in Cameroon. The Pan African Medical Journal, 28, 91. https://doi.org/10.11604/pamj.2017.28.91.10986.

[11] Obaji, N., Elom, H., Agwu, U., Nwigwe, C., Ezeonu, P., \& Umeora, O. (2013). Awareness and Practice of Breast Self-Examination among Market Women in Abakaliki, South East Nigeria. Annals of medical and health sciences research, 3(1), 7-12. https://doi.org/10.4103/2141-9248.109457.

[12] American Society of Breast Surgeons. (2019). Breast Self-Examination. Retrieved from https://breast360.org/topic/2015/02/03/breast-selfexamination-bse/.

[13] Sani, M.A, \& Naab, F. (2014). Relationship between Age and Breast Self-Examination among Women in Nigeria. International Organization of Scientific Research- Journal of Nursing and health Science, 3(6), 34-39.

[14] Jones, K. N. (2013). Imaging of the adolescent breast. Seminars in plastic surgery, 27(1), 29-35. https://doi.org/10.1055/s-0033-1343994.

[15] Ahmed, A., Zahid, I., Ladiwala, Z., Sheikh, R., \& Memon, A. S. (2018). Breast self-examination awareness and practices in young women in developing countries: A survey of female students in Karachi, Pakistan. Journal of education and health promotion, 7 ,

90 . https://doi.org/10.4103/jehp.jehp_147_17.

[16] Gwarzo, U.M.D, Sabitu, H. \& Idris, S.H. (2009). Knowledge and practice of breast selfexamination among female undergraduate students of Ahmadu Bello University Zaria, northwestern Nigeria. Annals of African Medicine, 8(1), 55-58.

[17] Ifediora, C. O., \& Azuike, E. (2018). Tackling breast cancer in developing countries: Insights from the knowledge, attitudes and practices on breast cancer and its prevention among Nigerian teenagers in secondary schools. Journal of Preventive Medicine and Hygiene. 59(4), 282-300. https://doi.org/10.15167/2421-

4248/jpmh2018.59.4.964.

[18] Nwachokor, F., Igbe, A. P., \& Forae, G. D. (2013). Histopathological review of breast tumour in children and adolescents in Delta State Nigeria. African journal of Paediatric Surgery, 10 (2), 65-7.

[19]Banjo, A. (2004). Overview of breast and cervical cancers in Nigeria are there regional variations. In Paper presentation at the International workshop on new trends in Management of breast and cervical cancers, Lagos, Nigeria.

[20] Ihekwaba, F. (1992). Breast cancer in Nigerian women. British Journal of Surgery, 79 (8):771-5.

[21] Usman, I.N., Olarenwaju, S.O., Usman, S. (2020). Breast Self-Examination Practice among Female Secondary School Students in Oshogbo, Western Nigeria. European Journal of Medical and Health Sciences, 2 (2) 173-180. https://doi.org//10.24018/ejmed.2020.2.2.173.

[22] Ohaeri, B.M., \& Achilonu, B.O. (2019). Nigerian students' awareness of breast selfexamination. African Journal of Midwifery and Women's Health, 13(1). https://doi.org/10.12968/ajmw.2019.13.1.34.

[23] Adetule, Y. C. (2016). Breast Self-Examination (BSE): A strategy for early detection of breast cancer in Nigeria. Annals of Oncology, 27(9). https://doi.org/10.1093/annonc/mdw575.020.

[24] Irurhe, N.K., Raji, J.B., Olowoyeye, A.O., Ademoye, R.A., Arogundade, R.O., Soyebi, K.O., et al. (2012). Knowledge and Awareness of breast cancer among female secondary school students in Nigeria. Academic journal of cancer research, 5 (1). $1-5$.

[25] Isara, A.R., \& Ojedokun, C.I. (2011). Knowledge of breast cancer and practice of breast self-examination among female secondary school student. Journal of Preventive medicine and hygiene, 52 (4), 186-190.

[26] Al-Haji, K.M \& Moawed, S.A. (2015). Breast Self-Examination Knowledge among Female High School Students in Riyadh City. Middle East. Journal of Nursing, 9(1), 25-27.

[27] Ranasinghe, H.M., Ranasinghe, N., Rodrigo, C., De A Seneviratne, R. \& Rajapaksa, S. (2013). Awareness of breast cancer among adolescent girls in Colombo, Sri Lanka: a school-based study. BMC Public Health. 13, 1209.

[28] Azubuike, S. O., Muirhead, C., Hayes, L., \& McNally, R. (2018). Rising global burden of breast cancer: the case of sub-Saharan Africa (with emphasis on Nigeria) and implications for regional development: a review. World journal of surgical oncology, 16(1), 63. https://doi.org/10.1186/s12957018-1345-2. 